\title{
On the influence of zonal gravity wave distributions on the Southern Hemisphere winter circulation
}

\author{
Friederike Lilienthal $^{1}$, Christoph Jacobi ${ }^{1}$, Torsten Schmidt ${ }^{2}$, Alejandro de la Torre ${ }^{3,4}$, and Peter Alexander ${ }^{4}$ \\ ${ }^{1}$ Institute for Meteorology, University of Leipzig, Leipzig, Germany \\ ${ }^{2}$ GFZ German Research Centre for Geosciences, Potsdam, Germany \\ ${ }^{3}$ Facultad de Ingeniería, Universidad Austral and CONICET, Buenos Aires, Argentina \\ ${ }^{4}$ Instituto de Fisica, CONICET, Buenos Aires, Argentina \\ Correspondence to: Friederike Lilienthal (friederike.lilienthal@ uni-leipzig.de)
}

Received: 24 January 2017 - Revised: 2 May 2017 - Accepted: 1 June 2017 - Published: 13 July 2017

\begin{abstract}
A mechanistic global circulation model is used to simulate the Southern Hemisphere stratospheric, mesospheric, and lower thermospheric circulation during austral winter. The model includes a gravity wave (GW) parameterization that is initiated by prescribed 2-D fields of GW parameters in the troposphere. These are based on observations of GW potential energy calculated using GPS radio occultations and show enhanced GW activity east of the Andes and around the Antarctic. In order to detect the influence of an observation-based and thus realistic 2-D GW distribution on the middle atmosphere circulation, we perform model experiments with zonal mean and 2-D GW initialization, and additionally with and without forcing of stationary planetary waves (SPWs) at the lower boundary of the model. As a result, we find additional forcing of SPWs in the stratosphere, a weaker zonal wind jet in the mesosphere, cooling of the mesosphere and warming near the mesopause above the jet. SPW wavenumber 1 (SPW1) amplitudes are generally increased by about $10 \%$ when GWs are introduced being longitudinally dependent. However, at the upper part of the zonal wind jet, SPW1 in zonal wind and GW acceleration are out of phase, which reduces the amplitudes there.
\end{abstract}

Keywords. Meteorology and atmospheric dynamics (middle atmosphere dynamics)

\section{Introduction}

The dynamics of the mesosphere and lower thermosphere (MLT) are largely determined by the mesospheric zonal jets and the influence of gravity waves (GWs) on the background circulation. GWs are mainly forced in the troposphere, the major sources being orography and convection. Propagating upward, they may encounter critical lines or break selectively depending on their intrinsic phase speed so that waves with phase speeds close to the background wind may only propagate if their amplitudes are small. Thus, in the upper mesosphere, mainly GWs with phase speeds in the opposite direction of the mean flow are remaining, and if these break they deposit momentum on the mean flow opposite to the mean flow, leading to the observed MLT wind reversal. GWs have horizontal wavelengths of tens to hundreds of kilometers; therefore they are at least partly of subgrid scale in global circulation models. This means that the waves have to be parameterized in circulation models and also their sources have to be described adequately. Climate models or weather forecasting models traditionally parameterize GW sources in the troposphere especially by mountain wave parameterizations, i.e., to improve, for example, tropospheric wind jets (M. J. Alexander et al., 2010; Geller et al., 2013).

Models for the middle atmosphere, however, use parameterizations not necessarily driven by source parameterization with regard to stratospheric and mesospheric dynamics. Their GW sources can be introduced by a particular prescribed GW distribution in the lower atmosphere. In mechanistic models, which are primarily used for sensitivity experiments, this distribution may be described by a simple function (e.g., Rose, 1983; Jakobs et al., 1986; Fröhlich et al., 2003a). Alternatively, one may describe the GW source distribution based on observed GW fields. Such observed fields can be obtained from radio occultation (RO) measurements based on radio links between a GPS satellite and a low-Earth 
orbiting (LEO) satellite (Kursinski et al., 1997). Since GPS ROs deliver temperature profiles in the upper troposphere and lower stratosphere, temperature fluctuations can be obtained by removing the background either through vertical or horizontal detrending (e.g., Tsuda et al., 2000; Gavrilov et al., 2004; Ern et al., 2011; Schmidt et al., 2016). Then, potential energy $E_{\mathrm{p}}$ can be obtained from the temperature fluctuations, and $E_{\mathrm{p}}$ is one measure for GW activity. Note that the GW source must be significant, the propagation conditions up to the measurement zone must be favorable and the waves must stay within the observational filter of the measurement technique in order to detect prominent GW activity. The first climatology of GPS RO $E_{\mathrm{p}}$ was presented by Tsuda et al. (2000) using GPS-MET satellite observations, but starting with the CHAMP mission (Wickert et al., 2001; Reigber et al., 2002) a much larger and increasing data base has become available (e.g., Ratnam et al., 2004; de la Torre et al., 2006) and high-resolution observations from the six-satellite constellation FORMOSAT-3/COSMIC and additional data sets are available.

In addition to the typical latitudinal distribution, some distinct non-zonal features in GW activity have been found based on GPS RO analyses. For example, Šácha et al. (2015) reported enhanced GW activity over eastern Asia. More frequently, enhanced GW activity has been reported over the Andes and the Antarctic Peninsula (e.g., de la Torre et al., 2012; Faber et al., 2013; Hindley et al., 2015; de Wit et al., 2017; Wright et al., 2017), which affects the middle atmosphere circulation and may even influence the ionosphere (de la Torre et al., 2014; Alexander et al., 2015). In general, GW activity as indicated by $E_{\mathrm{p}}$ calculated from GPS $\mathrm{RO}$ observations is essentially strong in the tropics and in some areas of the winter hemisphere, whereas it is generally weak in the summer part of the globe. The large amplitudes at equatorial latitudes are caused by convection. In the Northern Hemisphere $(\mathrm{NH})$ winter there is a significant orographic GW source located above Scandinavia (e.g., Ehard et al., 2016). As stated above, very intense GW activity has been found in the Southern Hemisphere (SH) to the east of the Andes mountains and the Antarctic Peninsula, which is mainly caused by topography (Eckermann et al., 1999; P. Alexander et al., 2010). The mountains in this entire region roughly represent a 2-D north-south obstacle for the intense prevailing zonal winds blowing from the west in the troposphere. In addition, conditions in this region are in general favorable for further upward propagation of the generated GWs to the stratosphere and beyond (de la Torre and Alexander, 2005; Baumgaertner and McDonald, 2007). Ern et al. (2004) have shown that GWs in this region may generate a very high stratospheric momentum flux as compared to other regions of the world. Here we are interested in the hemispheric effects of these localized GW enhancements. Šácha et al. (2016) have shown that a stronger GW forcing can lead to an increased planetary wave forcing and an enhanced BrewerDobson circulation. Therefore, to analyze the effect of such localized GW sources on the middle atmosphere mean circulation (zonal mean circulation and planetary waves) in the $\mathrm{SH}$, we use a mechanistic circulation model and initialize the GW parameterization scheme with different distributions of the GW sources, namely a zonal mean distribution and a 2D distribution, both based on observed $E_{\mathrm{p}}$ distribution. We analyze zonal mean parameters, stationary planetary waves (SPWs), and in particular changes of these parameters due to the non-zonal GW distribution. We focus on the SH winter, when GW activity in the SH is much larger than during summer, and when SPWs are able to propagate to the middle atmosphere. The remainder of this paper is organized as follows: in Sect. 2, the model as well as the experimental setup is described including the $E_{\mathrm{p}}$ analysis from GPS RO used for the GW initialization. Section 3 presents results of the model experiments. Section 4 concludes the paper.

\section{MUAM Model experiments}

\subsection{Model description and analysis}

For the numerical experiments we employ the Middle and Upper Atmosphere Model (MUAM; Pogoreltsev et al., 2007), which is a 3-D mechanistic model of the neutral atmospheric circulation extending from the $1000 \mathrm{hPa}$ surface up to the thermosphere. It is based on the Cologne Model of the Middle Atmosphere - Leipzig Institute for Meteorology (COMMA-LIM; Fröhlich et al., 2003a, b; Jacobi et al., 2006). The MUAM is a grid-point model with horizontal (latitude/longitude) resolution of $5^{\circ} \times 5.625^{\circ}$, and with up to 60 levels evenly spaced in the non-dimensional log-pressure height $x=\ln \left(p_{s} / p\right)$ with $p$ as pressure, and $p_{s}=1000 \mathrm{hPa}$ as a reference pressure. The step size is constant with $x=$ 0.4 , which corresponds to $2.842 \mathrm{~km}$ in log-pressure height $h=x \cdot H$ and $H$ as the scale height of $7 \mathrm{~km}$. The model allows using an arbitrary number of levels (ranging from 48 to $60)$ with the same vertical resolution. In the 56-level version used here the upper boundary is placed at $x=22.4$, which corresponds to a log-pressure height of about $150 \mathrm{~km}$ and a geopotential height of about $300 \mathrm{~km}$ depending on the thermospheric temperature. However, in the analysis we restrict ourselves to the mesosphere and lowermost thermosphere because we are interested in the GW mean flow interaction in the mesosphere here.

The model solves the primitive equations in flux form at a time step of $225 \mathrm{~s}$ in the 56-level version following a Matsuno integration scheme (Matsuno, 1966). The basic model dynamics equations are given, for example, by Jakobs et al. (1986). MUAM includes infrared and solar radiation parameterizations to enable the forcing of solar tides through ozone and water vapor absorption. Ozone and water vapor fields are prescribed. Because the model does not include a detailed troposphere, zonal mean temperatures from ERA-Interim reanalyses (Dee et al., 2011) are assimilated in the troposphere 

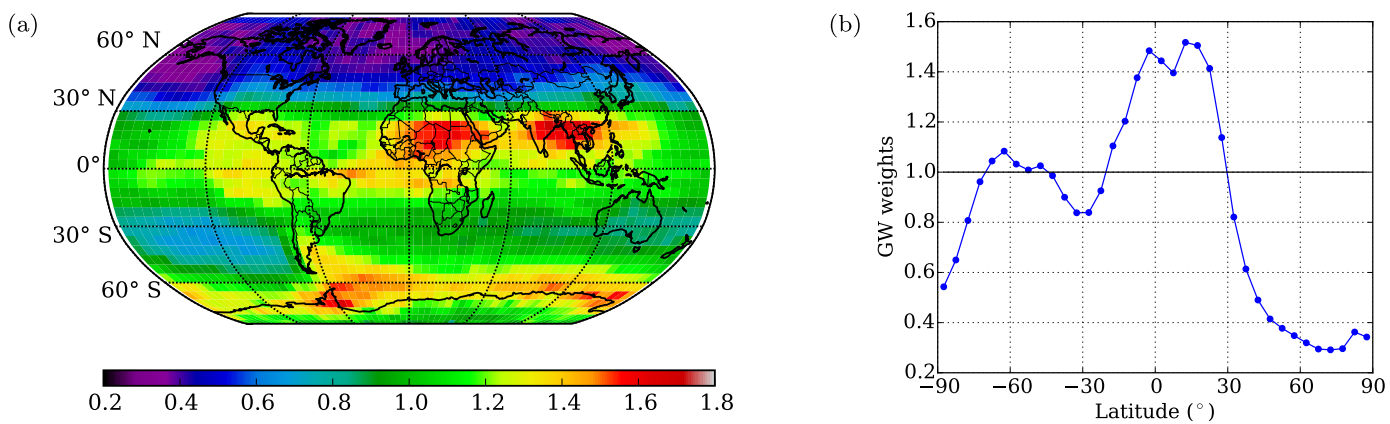

Figure 1. Horizontal field of GW weights (a) and their zonal means (b). GW weights are derived from the field of potential energy (from GPS RO measurements) averaged over a vertical column of 25.0-34.9 km altitude for the time interval 2007-2013. Then, each grid point is divided by the global mean value of potential energy for this vertical column. The grid is finally interpolated to the model grid.

and lower stratosphere below $30 \mathrm{~km}$. SPWs of wavenumber 1-3 taken from reanalyses of temperature and geopotential are assimilated at the lower boundary at $1000 \mathrm{hPa}$. We use 2000-2010 mean July mean zonal mean temperatures and SPW amplitudes and phases, while SPW amplitudes are averaged arithmetically and phases have been vector averaged from monthly means of the individual years. For a given run, we analyze 30 days of data (analyzing less or more days leads to nearly the same results) after a 330-day spin-up time during which SPWs and tides in the upper atmosphere develop until a stable situation is reached. During the 30-day analysis interval, which represents July conditions, we nudge ERA-Interim data that are constant in time in the lower atmosphere. Therefore, the modeled day-to-day variability is very small.

The GW parameterization currently used in MUAM is based on the linear one by Jakobs et al. (1986) but extended especially for multiple breaking levels (Fröhlich et al., 2003a, b; Jacobi et al., 2006; Pogoreltsev et al., 2007). The GWs are included in the model in the upper troposphere at $10 \mathrm{~km}$, and the global amplitude distribution is prescribed. This is usually realized using a simple zonal mean amplitude distribution. It is adjusted in such a way that the global mean vertical wind amplitude at the forcing level is $1.7 \mathrm{~cm} \mathrm{~s}^{-1}$. This value has been chosen in order to tune the circulation of the middle atmosphere, i.e., the magnitude of the jets and the altitude of the respective wind reversals. In the GW parameterization, 48 waves are initialized with six different phase speeds in eight directions. The GW parameterization routine is run every $2 \mathrm{~h}$ of modeled time, and the initial conditions are kept constant. As a result, the parameterization derives GW momentum fluxes and the acceleration of the mean flow due to GWs. These parameters are presented below.

In the following sections we also present SPW amplitudes of certain parameters and the Eliassen-Palm (EP) flux and its divergence. SPW amplitudes are obtained using a harmonic analysis for each altitude level and each latitude, separately. Thereby we assume that the respective parameter is given by a superposition of its zonal mean, SPW1, SPW2, and SPW3 and a migrating diurnal tide and we apply a least-squares fit, accordingly. The calculation of the EP flux and its divergence follows Andrews et al. (1987) and is normalized by the factor $\rho_{0} \cdot a \cdot \cos \phi$, where $\rho_{0}$ is the density, $a$ the radius of the Earth, and $\phi$ the geographic latitude.

\subsection{Stratospheric GW fields and experimental setup}

To initiate the GWs in our experiment, we apply a realistic GW climatology that is based on GPS RO $E_{\mathrm{p}}$ distributions. $E_{\mathrm{p}}$ is calculated using temperature profiles in the stratosphere derived from RO using FORMOSAT-3/COSMIC and MetOP satellites (CDAAC, 2015). The method is based on temperature anomalies in grids of $5^{\circ} \times 10^{\circ}$ in latitude and longitude that have been calculated after horizontal detrending, i.e., after removing zonal mean and wavenumbers 1-6 (Schmidt et al., 2016) from the temperature observations. Data from 2007-2013 with vertical steps of $100 \mathrm{~m}$ have been used (note that the true resolution is lower), which have been averaged over $25.0-34.9 \mathrm{~km}$ altitude. $E_{\mathrm{p}}$ from the troposphere at $10 \mathrm{~km}$, i.e., directly from the launch level of GWs in MUAM, cannot be used because temperature residuals there are not only due to GWs but also to mesoscale circulation systems. In our model experiment we use 2-D (Fig. 1a) and zonal mean (Fig. 1b) GW distributions based on the long-term observations of $E_{\mathrm{p}}$ normalized by their global average. In the model, these values are multiplied with a given initial GW amplitude, i.e., $1.7 \mathrm{~cm} \mathrm{~s}^{-1}$ for the vertical wind perturbation so that the global average initial $\mathrm{GW}$ amplitude is $1.7 \mathrm{~cm} \mathrm{~s}^{-1}$ as well. In Fig. 1a one can see an enhancement of $E_{\mathrm{p}}$ near the Equator that is due to convective GWs, and large values around $60^{\circ} \mathrm{S}$, connected with the polar vortex. Higher values over India and Southeast Asia are probably due to the effect of the summer monsoon (M. J. Alexander et al., 2010; Geller et al., 2013). Further enhancement is visible east of the Andes and above all around the Antarctic Peninsula as has been reported, for example, by de la Torre et al. (2012) and Hindley et al. (2015). 
(a)

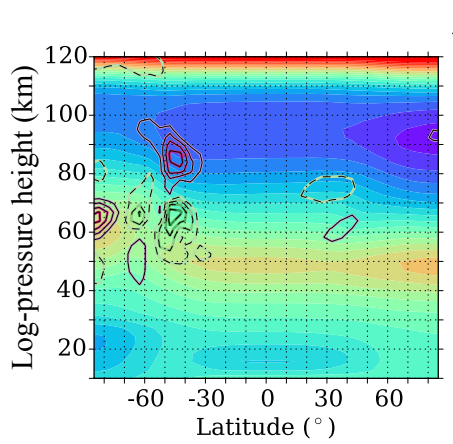

(c)

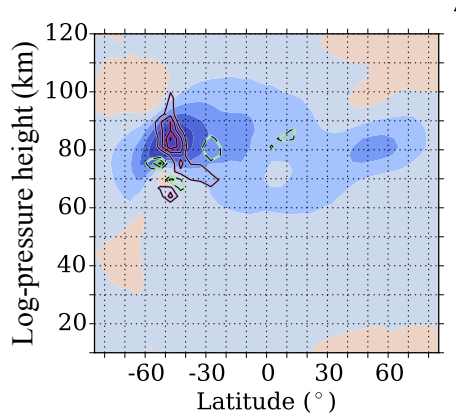

(e)
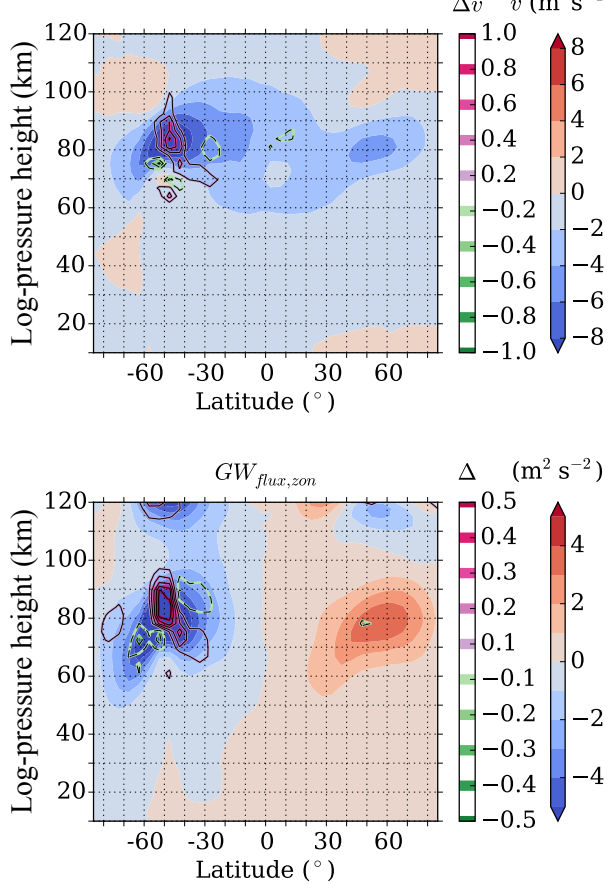

(b)

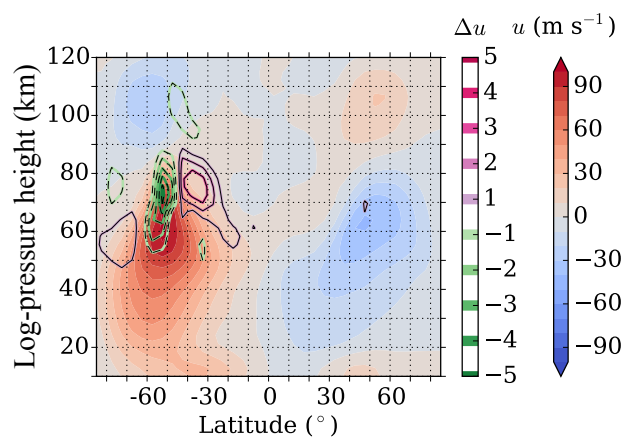

(d)

(f)

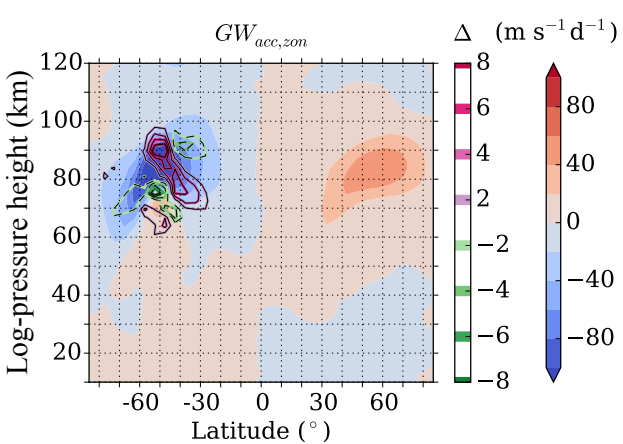

Figure 2. Background colors: Run1 zonal mean parameters for (a) temperature, (b) zonal wind, (c) meridional wind, (d) vertical wind, (e) zonal GW momentum flux, and (f) zonal acceleration of the mean wind by GWs. Isolines: differences of these parameters for Run2Run1. For Run1, GW weights in the GW parameterization routine have been selected as zonal means according to Fig. 1b while Run2 includes a 2-D horizontal field according to Fig. 1a..

In the following we will refer to the run using zonal mean GW weights according to Fig. $1 \mathrm{~b}$ as Run1. It will serve as a reference. In a second run, we initiate the GW parameterization using the normalized 2-D GW fields from Fig. 1a. We refer to this run as Run2. The differences between these runs therefore can be attributed to the influence of the nonzonal GW distribution on the mean circulation and on the SPW activity. To check this, we performed further runs that do not include SPW forcing at the lower boundary with a 2-D GW source field (Run3) and zonal mean GW weights (Run4). SPWs in Run3 therefore should be solely due to the effect of non-zonal GW drag on the mean flow while Run4 represents the results for the absence of SPWs. Table 1 gives an overview on the experimental setups.
Table 1. Overview on the model runs and their setup.

\begin{tabular}{lcr}
\hline Run & GW weights & SPW forcing \\
\hline Run1 & 1-D & yes \\
Run2 & 2-D & yes \\
Run3 & 2-D & no \\
Run4 & 1-D & no \\
\hline
\end{tabular}

1-D is zonal mean and 2-D is horizontal field. 
(a)

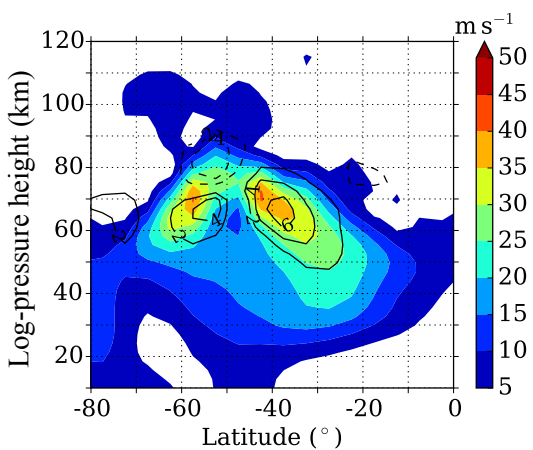

(c)

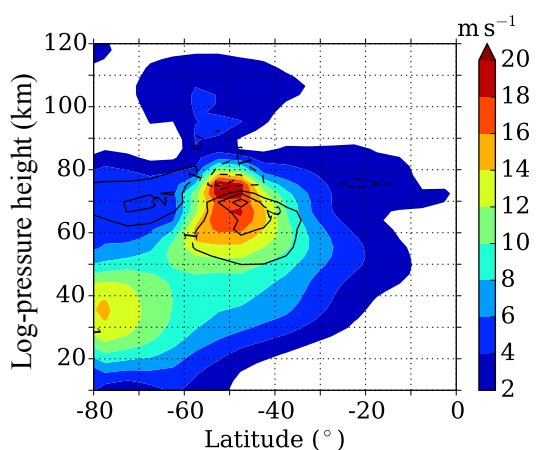

(e)

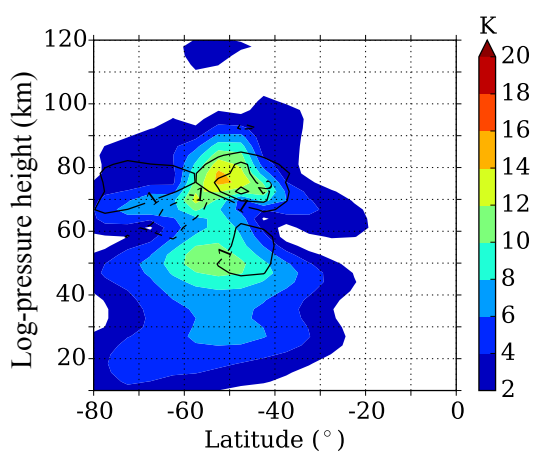

(b)

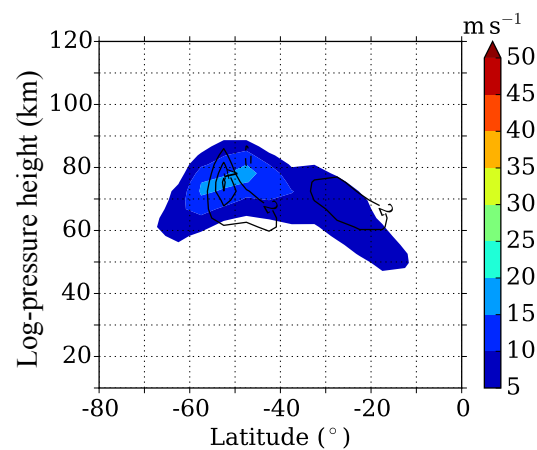

(d)

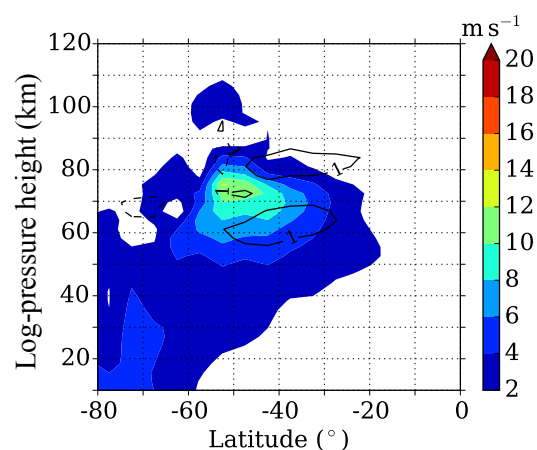

(f)

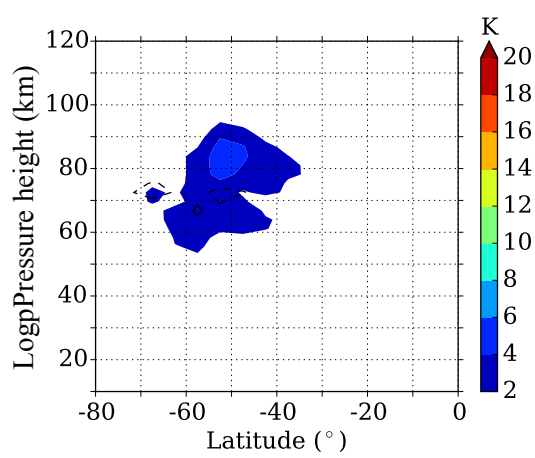

Figure 3. Run1: zonal wind (a, b), meridional wind (c, d) and temperature (e, f) amplitudes of SPW1 (left column: a, c, e) and SPW2 (right column: b, d, f) as background colors. Run2-Run1 differences are added as isolines in steps of $2 \mathrm{~m} \mathrm{~s}^{-1}$ (zonal wind), $1 \mathrm{~ms} \mathrm{~s}^{-1}$ (meridional wind) and $1 \mathrm{~K}$ (temperature).

\section{Results}

\subsection{Climatology for zonal mean and 2-D GW amplitudes with SPW forcing}

The background colors of Fig. 2 show July mean conditions of zonal mean background dynamics for the zonal mean GPS RO run with SPW forcing at the lower boundary (Run1). Run2-Run1 differences are added as isolines. The respective panels show zonal mean temperature (a), zonal wind (b), meridional wind (c) and vertical wind (d). Zonal GW fluxes and zonal wind acceleration are shown in Fig. 2e and $\mathrm{f}$.

For the reference Run1 we note a realistic temperature distribution (Fig. 2a), but a relatively strong mesospheric jet in the winter hemisphere with wind speeds up to $110 \mathrm{~m} \mathrm{~s}^{-1}$ (Fig. 2b). Due to this strong eastward wind jet, GWs can reach high intrinsic phase speeds and thus they are able to penetrate to high altitudes of the atmosphere before they reach their individual breaking level. That is why the wind jet is only decelerated by GWs above $80 \mathrm{~km}$ at about $50^{\circ} \mathrm{S}$ (Fig. 2f), while poleward and equatorward of the jet the deceleration begins already at lower altitudes. Below the jet maximum, GW acceleration is positive (eastward) - i.e., mainly eastward propagating GWs are breaking at these altitudes. At higher midlatitudes, this strong wind jet and high altitude of GW mean flow interaction also leads to a relatively high and strong meridional wind jet (Fig. 2c) and a distinct maximum of the downward wind (Fig. 2d). The meridional GW flux and acceleration (not shown here) is smaller by more than a factor of 2 than the zonal flux and it is northward directed, opposite to the mean meridional wind. 
(a)

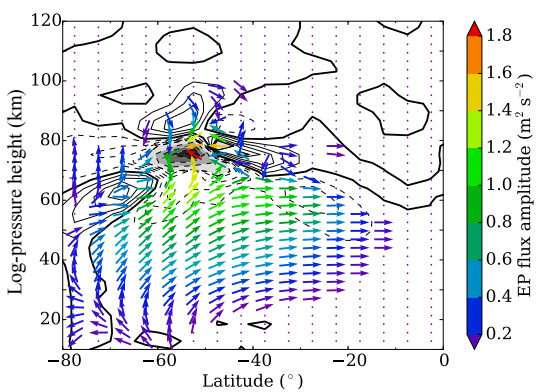

(c)

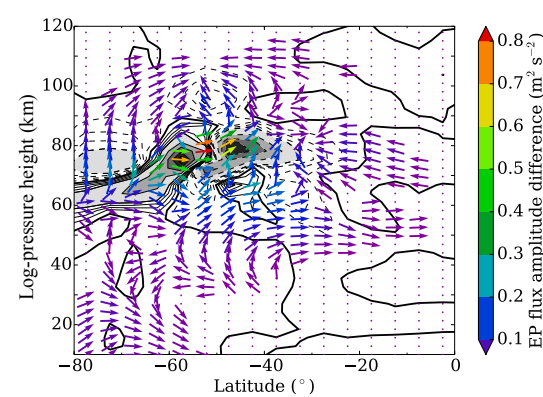

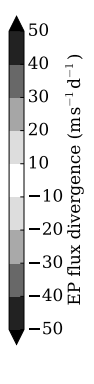

(b)

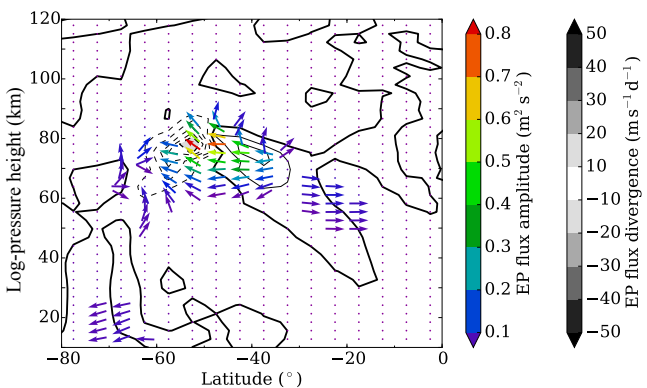

(d)

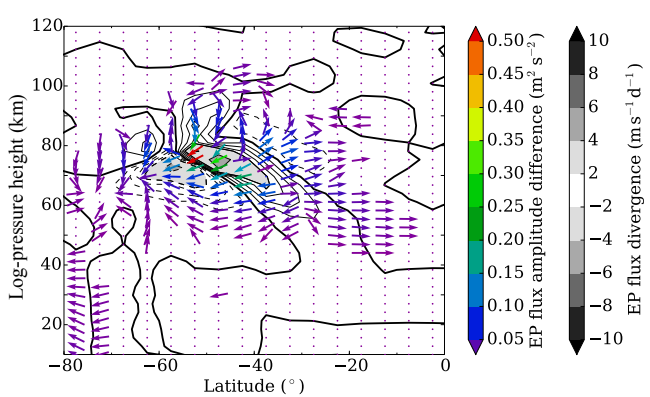

Figure 4. Run1 EP flux vectors for SPW1 (a) and SPW2 (b). Normalized arrows represent the direction of EP flux. EP flux components are scaled by $\rho_{0} a \cos \phi$, and their amplitude (in $\mathrm{m}^{2} \mathrm{~s}^{-2}$ ) is given by color coding. Only points where the amplitude is less than $1 \%$ of the maximum amplitude in the field are shown. EP flux divergence, also scaled by $\rho_{0} a \cos \phi$, is added as solid (dashed) isolines for positive (negative) values. Contour intervals are $2 \mathrm{~m} \mathrm{~s}^{-1} \mathrm{~d}^{-1}$ between -10 and $10 \mathrm{~m} \mathrm{~s}^{-1} \mathrm{~d}^{-1}$, and otherwise $10 \mathrm{~m} \mathrm{~s}^{-1} \mathrm{~d}^{-1}$ starting from $\pm 10 \mathrm{~m} \mathrm{~s}^{-1} \mathrm{~d}^{-1}$ (also indicated in gray). Run2-Run1 differences are shown in (c) for SPW1 and (d) for SPW2. Here, isolines have intervals of $0.5 \mathrm{~m} \mathrm{~s}^{-1} \mathrm{~d}^{-1}$ between -2 and $2 \mathrm{~m} \mathrm{~s}^{-1} \mathrm{~d}^{-1}$ and otherwise $2 \mathrm{~m} \mathrm{~s}^{-1} \mathrm{~d}^{-1}$ starting from $\pm 2 \mathrm{~m} \mathrm{~s}^{-1} \mathrm{~d}^{-1}$ (also indicated in gray).

The differences between Run2 and Run1 are also shown by contour lines in Fig. 2. They represent the effect of a nonzonal GW forcing in the model based on $E_{\mathrm{p}}$ distributions shown in Fig. 1a. We note a complicated structure of GW acceleration change near the zonal wind jet maximum (Fig. 2f). Slightly below $70 \mathrm{~km}$ at about $50^{\circ} \mathrm{S}$ we note more eastward acceleration (positive differences), but the zonal wind jet is nevertheless reduced. This can be explained in Fig. $4 \mathrm{c}$ below, showing the SPW wavenumber 1 (SPW1) differences of EP flux and its divergence between Run2 and Run1: the EP flux divergence is stronger (more negative) in this region and this results in stronger deceleration of the westerly wind. Slightly below the zonal wind maximum, between 70 and $80 \mathrm{~km}$, the negative GW flux divergence increases (negative differences) - i.e., we have stronger deceleration of the zonal wind. Above $80 \mathrm{~km}$, there is again weaker westward acceleration. This pattern is more or less directly visible in the meridional wind (Fig. 2c), which is reduced above $80 \mathrm{~km}$ (positive changes) and increased below. Note, however, that around $70 \mathrm{~km}$ at $50^{\circ} \mathrm{S}$ there is a small area of equatorward wind, and the negative change there means a decrease again. In summary, we have a localized deceleration of the meridional wind, and this is connected with a vertical wind structure change (Fig. 2d) with upward vertical anomalies directly above the jet and downward ones at the flanks of the jet, especially at the equatorward one. There one finds warming in the lower thermosphere (red isolines in Fig. 2a), and in the mesosphere there is a cooling connected with the upward wind anomaly.

The background colors of Fig. 3 show the zonal wind (top), meridional wind (middle) and temperature amplitudes (bottom) of SPW wavenumber 1 (SPW1, left) and wavenumber 2 (SPW2, right) from the MUAM Run1. We show only the winter hemisphere, because the wave amplitudes are particularly weak in the summer hemisphere. Maximum SPW1 amplitudes are $41 \mathrm{~m} \mathrm{~s}^{-1}$ (Fig. 3a) and $20 \mathrm{~m} \mathrm{~s}^{-1}$ (Fig. 3c) for the zonal and meridional wind, respectively, and $15 \mathrm{~K}$ (Fig. 3e) for the temperature. Temperature and meridional wind amplitude maxima are found above the maximum of the zonal wind jet (Fig. 3c and e), and maximum zonal amplitudes are found directly north and south of this region at about $70 \mathrm{~km}$ altitude (Fig. 3a). In the stratosphere, there is also a SPW1 at high latitudes (Fig. 3a and c), which represents a slight vortex displacement. SPW2 amplitudes are smaller than SPW1 ones approximately by a factor of 2 , while their spatial distribution is similar to that of SPW1 amplitudes. Amplitudes of higher wavenumbers are even smaller, so we do not show them here.

Implementing non-zonal structures in the input fields of the GW parameterization leads to generally increased SPW1 and SPW2 amplitudes with regard to the zonal mean run. This can be seen in Fig. 3 indicated by black isolines within the panels. The increase in amplitude amounts to about $10 \%$. Note, however, that for the zonal and meridional wind waves 


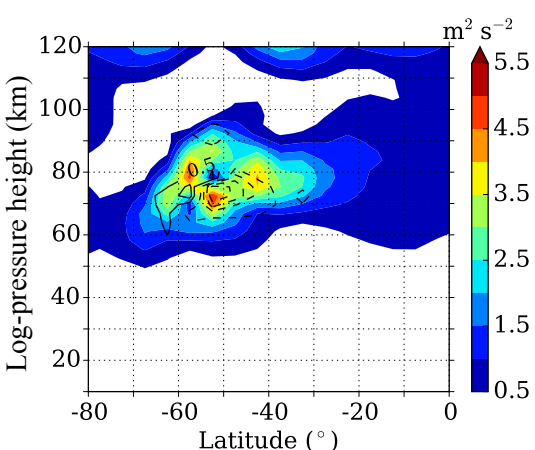

(c)

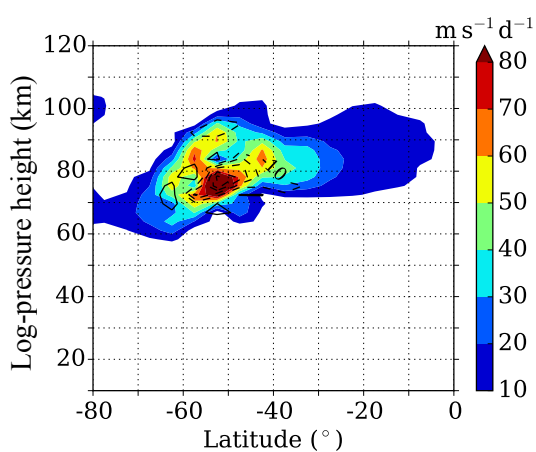

(b)

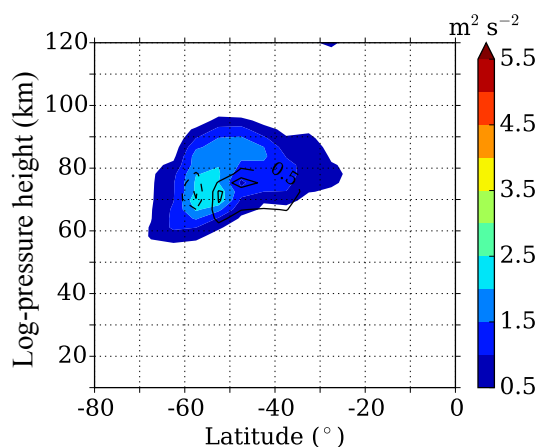

(d)

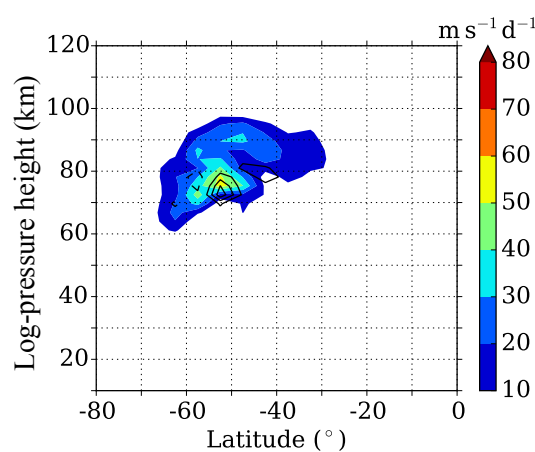

Figure 5. Background colors: Run1 zonal GW flux amplitudes of SPW1 (a) and SPW2 (b) and GW acceleration amplitudes of SPW1 (c) and SPW2 (d). Run2-Run1 differences are added as isolines in intervals of $0.5 \mathrm{~m}^{2} \mathrm{~s}^{-2}(\mathbf{a}, \mathbf{b})$ and $10 \mathrm{~m} \mathrm{~s}^{-1} \mathrm{~d}^{-1}$ (c, d), respectively.

there is also a slight decrease around $80 \mathrm{~km}$ near the upper part of the mesospheric zonal wind jet. This is due to an out of phase relationship of SPWs in background parameters and GW acceleration, which will be shown for SPW1 in Fig. 11 below. The increased SPW1 are connected with stronger upward EP flux at midlatitudes (at about $50^{\circ} \mathrm{S}$ and above $40 \mathrm{~km}$ ), and more negative EP flux divergence at midlatitudes (Fig. 4c). This is reflected in the stronger zonal wind between 40 and $30^{\circ} \mathrm{S}$ and 70 and $80 \mathrm{~km}$ in Fig. 2b. Poleward, the EP flux divergence increases - i.e., we have more eastward acceleration and weaker zonal winds. For SPW2 the situation is reversed (Fig. 4d) - i.e., we have westward acceleration of the mean flow at higher latitudes and eastward acceleration at midlatitudes. However, the magnitude of SPW2 acceleration is smaller than that of SPW1 (Fig. 4a, b), again approximately by a factor of 2 as is the case with the amplitudes. Therefore the SPW1 effect outweighs that of SPW2 and we see the corresponding changes in the zonal prevailing wind.

The SPW EP fluxes and their divergence show an equatorward propagation of SPWs in the lower stratosphere north of $70^{\circ} \mathrm{S}$ for SPW1 (Fig. 4a) and north of $50^{\circ} \mathrm{S}$ for SPW2 (Fig. 4b). For higher latitudes, there is poleward propagation. Above $60 \mathrm{~km}$ (SPW1, Fig. 4a) we find again upward propagation. The SPW2 (Fig. 4b) describes reversed horizontal propagation direction above $55 \mathrm{~km}$ between 40 and $60^{\circ} \mathrm{S}$. Both SPW1 and SPW2 show a broad region of negative EP divergence (i.e., westward acceleration) at about $55^{\circ} \mathrm{S}$ and
$80 \mathrm{~km}$ altitude, which covers broadly the westerly wind jet so that SPWs lead to a deceleration of the mean flow. A smaller region of eastward acceleration (positive EP flux divergence) is found at the poleward flank of the zonal wind jet.

According to our experimental setup (see Table 1), the SPWs of Run1 (see Fig. 3) are due to their direct forcing at $1000 \mathrm{hPa}$ (obtained from ERA reanalyses) because no other direct sources of SPWs are included in that experiment. However, there is a possible secondary PW forcing due to modulation of GWs and their modulated breaking. This can be visualized by splitting GW parameters into their latitudinal mean and their wave structures, i.e., by analyzing their SPW amplitudes, which are larger than zero when a modulation is present. This can be seen in Fig. 5 showing the SPW1 (left) and SPW2 (right) amplitudes in zonal GW flux (Fig. 5a, b) and acceleration (GW flux divergence; Fig. 5c, d). Maximum SPW acceleration due to non-zonal GW breaking is seen slightly below $80 \mathrm{~km}$ between 50 and $60^{\circ} \mathrm{S}$, where the secondary peak in SPW temperature forms, as is seen from Fig. 3e.

The differences between Run2 and Run1 for SPW1 and SPW2 amplitudes of GW flux and GW acceleration are shown as isolines in Fig. 5. We note that SPW1 amplitudes are reduced below $80 \mathrm{~km}$ near the jet maximum (Fig. 5a, c), which corresponds with the reduced SPW1 wind amplitudes above (see Fig. 3a, c). This structure is not seen in SPW2, where we have increased SPW2 structure in GW flux and divergence when 2-D structures in GW forcing are taken into 
(a)

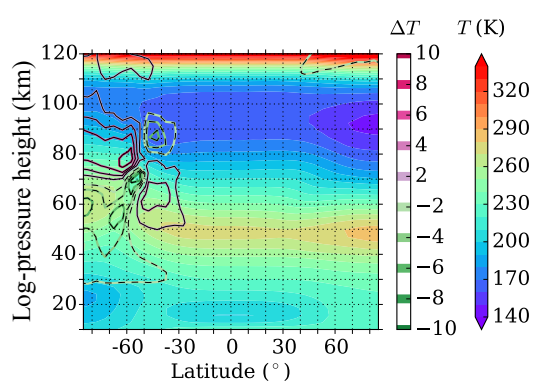

(c)

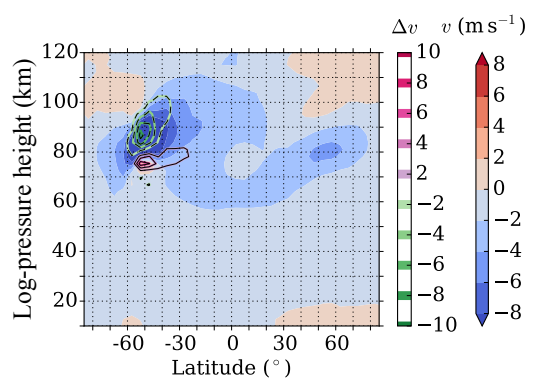

(e)

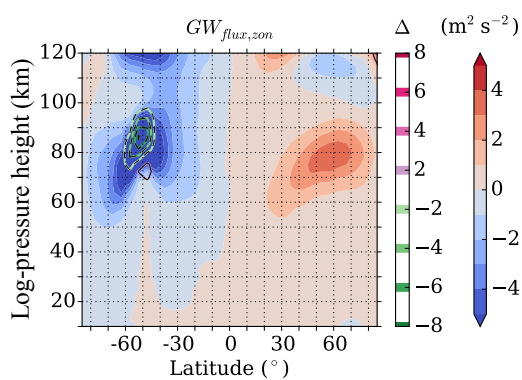

(b)

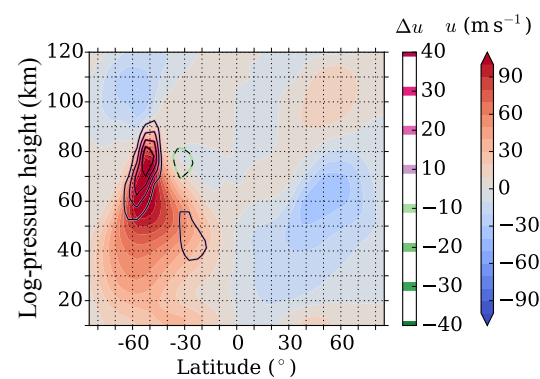

(d)

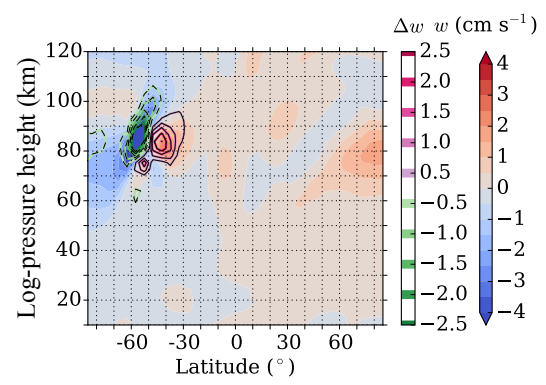

(f)

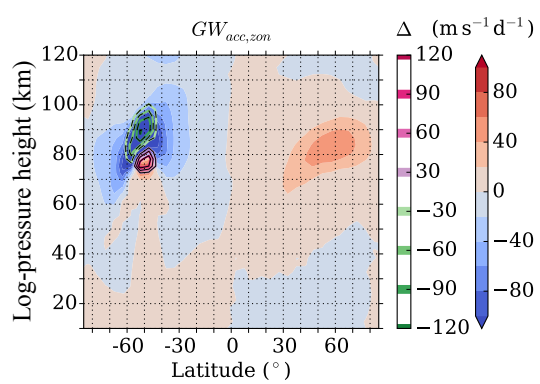

Figure 6. Background colors: Run3 zonal mean parameters for (a) temperature, (b) zonal wind, (c) meridional wind, (d) vertical wind, (e) zonal GW momentum flux, and (f) zonal acceleration of the mean wind by GWs. Isolines: differences of these parameters for Run3Run2. For both runs, GW weights in the GW parameterization routine have been selected as a 2-D horizontal field according to Fig. 1a, but for Run2 SPW forcing is enabled and disabled for Run3.

account (Fig. 5b, d). GW SPW amplitudes in Run1 exist due to zonal inhomogeneities in GW propagation conditions (mean wind) only. We may conclude that GW non-zonal structures through GW non-zonal sources obviously counteract SPW1 in GW flux due to SPW1 in background circulation. Indeed we note that SPW1 phases from GWs due to SPW1 in background flow (Run1) and those from GWs due to non-zonal GW forcing (Run3) are out of phase in that region (see Fig. 10 below). Around $60^{\circ} \mathrm{S}$, GW flux SPW1 increases in Run2, and this corresponds with near-zero phase differences in Fig. 10 there.

\subsection{MUAM climatology without SPW forcing at the lower boundary}

For the third experiment, Run3, no SPWs are forced at the lower model boundary, but the initial GW amplitudes have a 2-D distribution. Consequently, all the SPWs seen in this run are due to GW non-zonal structures. However, we do not expect the remaining SPWs to be absolutely equal to the dif- ferences between Run2 and Run1 as shown in Fig. 3, because the missing background SPWs in Run3 lead to a modified zonal mean background circulation in the middle atmosphere, and then in turn to modified GW and SPW propagation conditions. Analogue to Fig. 3, the zonal mean winds, temperatures, and GW parameters are shown in Fig. 6. Differences are added for Run3-Run2 and represent the direct influence of a removed SPW forcing at the lower boundary. As expected, the zonal wind jet is strongly (and unrealistically) accelerated in its upper part (Fig. 7b), which leads to a GW propagation to higher altitudes and therefore to acceleration of the poleward (Fig. 7c) and downward (Fig. 7d) winds above $80 \mathrm{~km}$. The opposite is the case below $80 \mathrm{~km}$ as well as equatorward of $50^{\circ} \mathrm{S}$. Consequently, we find warming at the mesopause and cooling in the stratosphere and mesosphere (Fig. 7a) poleward of $50^{\circ} \mathrm{S}$ and a reversed structure equatorward.

Comparing the remaining SPWs due to non-zonal GW structures in Fig. 7 with the differences between Run2 and 
(a)

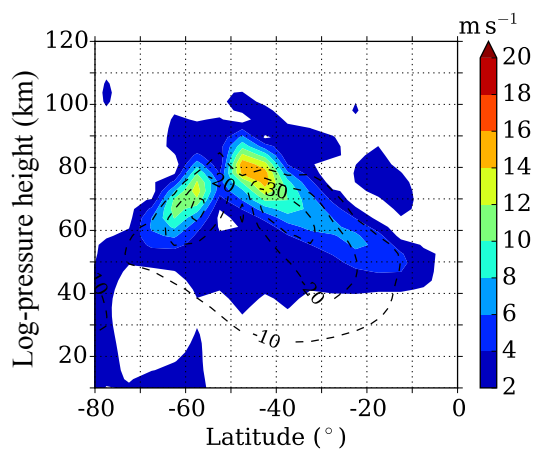

(c)

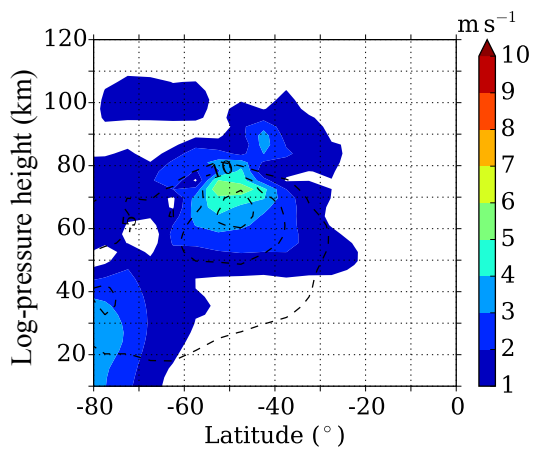

(e)

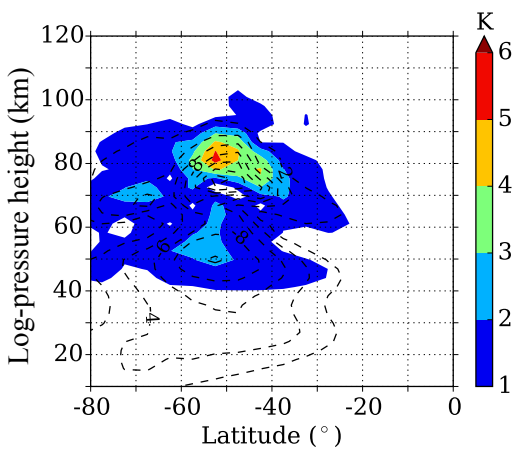

(b)

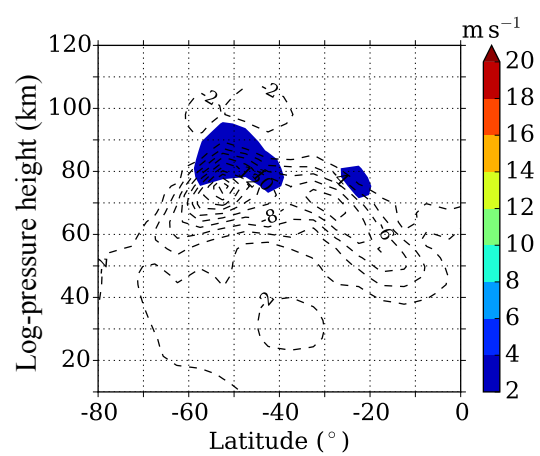

(d)

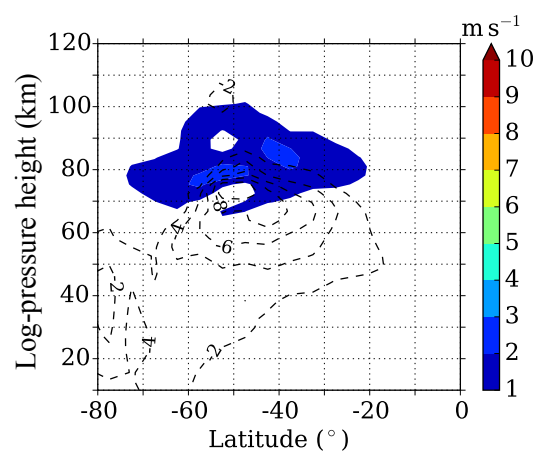

(f)

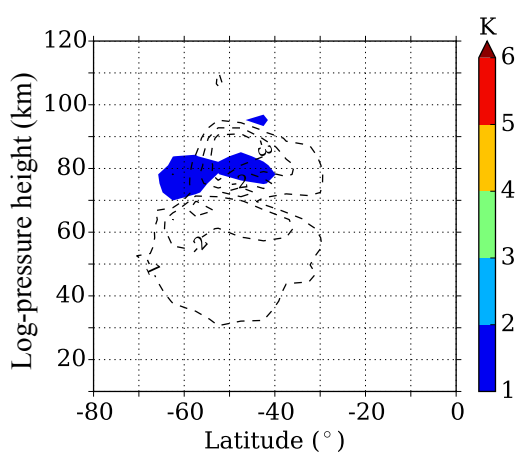

Figure 7. Run3: zonal wind (a, b), meridional wind (c, d) and temperature (e, f) amplitudes of SPW1 (left column: a, c, e) and SPW2 (right column: b, d, f) as background colors. Run3-Run2 differences are added as isolines in steps of $10 \mathrm{~m} \mathrm{~s}^{-1}(\mathbf{a}, \mathbf{c}), 2 \mathrm{~m} \mathrm{~s}{ }^{-1}$ (b, d), $2 \mathrm{~K}(\mathbf{e})$, and $1 \mathrm{~K}(\mathbf{f})$.

(a)

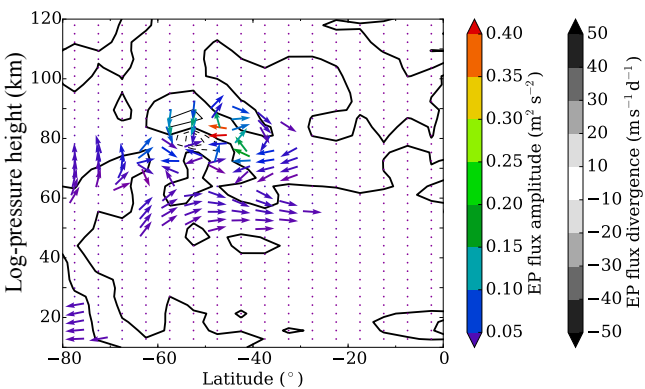

(b)

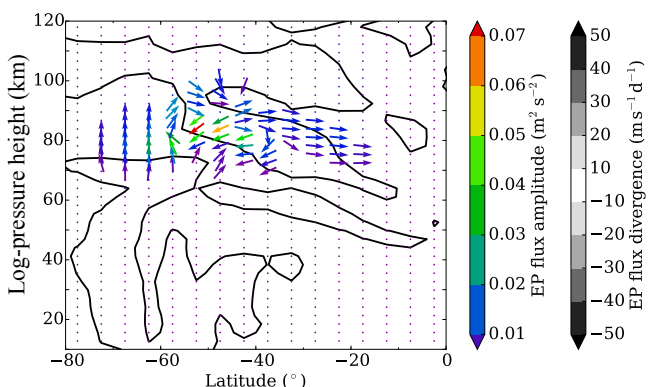

Figure 8. Run3 EP flux vectors for SPW1 (a) and SPW2 (b). Normalized arrows represent the direction of EP flux. EP flux components are scaled by $\rho_{0} a \cos \phi$, and their amplitude (in $\mathrm{m}^{2} \mathrm{~s}^{-2}$ ) is given by color coding. Only points where the amplitude is less than $1 \%$ of the maximum amplitude in the field are shown. EP flux divergence, also scaled by $\rho_{0} a \cos \phi$, is added as solid (dashed) isolines for positive (negative) values. Contour intervals are $2 \mathrm{~m} \mathrm{~s}^{-1} \mathrm{~d}^{-1}$ between -10 and $10 \mathrm{~m} \mathrm{~s}^{-1} \mathrm{~d}^{-1}$, and otherwise $10 \mathrm{~m} \mathrm{~s}^{-1} \mathrm{~d}^{-1}$ starting from $\pm 10 \mathrm{~m} \mathrm{~s}-1 \mathrm{~d}^{-1}$ (also indicated in gray). 
(a)

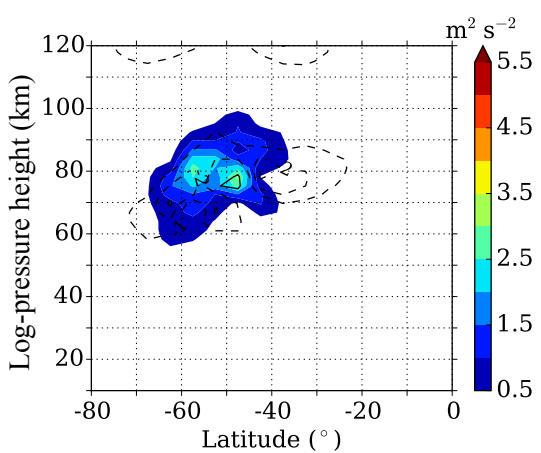

(c)

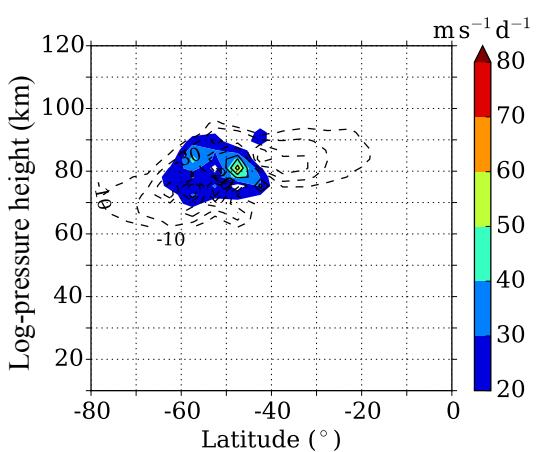

(b)

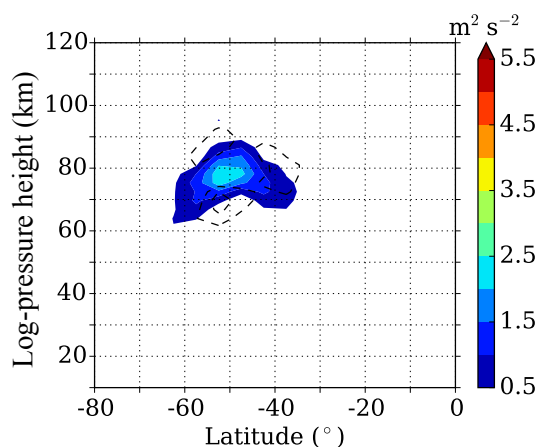

(d)

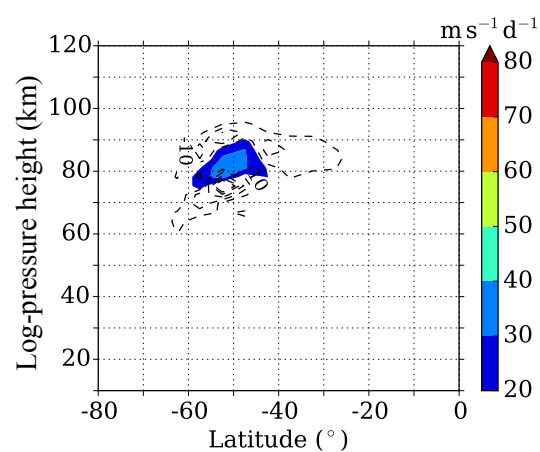

Figure 9. Background colors: Run3 zonal GW flux amplitudes of SPW1 (a) and SPW2 (b) and GW acceleration amplitudes of SPW1 (c) and SPW2 (d). Run3-Run2 differences are added as isolines in intervals of $1 \mathrm{~m}^{2} \mathrm{~s}^{-2}$ (a, b) and $10 \mathrm{~m} \mathrm{~s}^{-1} \mathrm{~d}^{-1}$ (c, d), respectively.

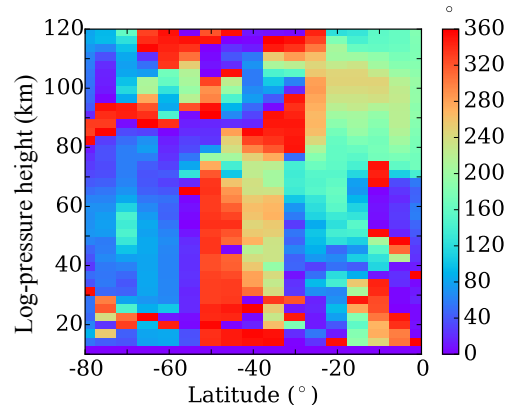

Figure 10. Run3-Run1 phase differences of zonal GW flux SPW1.

Run1 in Fig. 3, one may see that the amplitudes (especially of SPW1) are slightly larger in Run3, and the structures are shifted a bit upwards. This is connected with the upward shift of the wind systems when no SPWs are forced at the lower boundary (see Fig. 6). Remaining SPW1 EP fluxes (Fig. 8) are smaller than the differences in Fig. 4c and d, and the structure is different in the stratosphere. The remaining SPW2 flux is small.

SPW1 and SPW2 in GW flux and acceleration from Run3 are shown in Fig. 9 in order to demonstrate the SPW forcing due to non-zonal GWs. We find that the maximum GW amplitude is about half as large than the one for Run2 with SPWs forced at the lower boundary. We also find that the GW amplitudes are larger than the differences between Run2 and Run1 (Fig. 3). This is due to destructive interference between GWs forced by non-zonal sources and SPWs. We see in Fig. 10, showing Run3-Run1 phase differences of zonal GW flux SPW1, that below $80 \mathrm{~km}$ and between 40 and $50^{\circ} \mathrm{S}$ we have a region where these GW SPW1 are out of phase. This means that GW non-zonal structures may lead to additional SPW1 forcing in the stratosphere and increased upward EP flux, but the secondary forced PW may be out of phase with the original one, and then SPW1 amplitudes are reduced in the upper mesosphere (see left panels of Fig. 3).

The direct effect of non-zonal GW forcing on the SPWs can also be seen by comparing the phases of the SPWs in background flow and GWs. Figure 11 shows the phases of the zonal wind SPW1 from Run1, i.e., with SPWs only forced at the lower boundary, and the phases of the SPW1 in GW zonal wind acceleration from Run3, with SPWs only forced by the 2-D GW distribution in the GW parameterization routine. Between 50 and $60^{\circ} \mathrm{S}$ and below $70 \mathrm{~km}$ the two waves are approximately in phase; however, near the upper part of the zonal wind jet, around $80 \mathrm{~km}$, the waves are out of phase. This means that GW 2-D forcing amplifies the SPW1 in most of the middle atmosphere, but reduces its amplitude in the uppermost mesosphere. This corresponds to the amplitude distribution shown in Fig. 3.

For comparison, we also performed a run without SPW forcing and with a zonal mean GW distribution (Run4). As expected in our idealized model setup, we do not see any wave structures in this run. Therefore, effects of non-zonal 
(a)

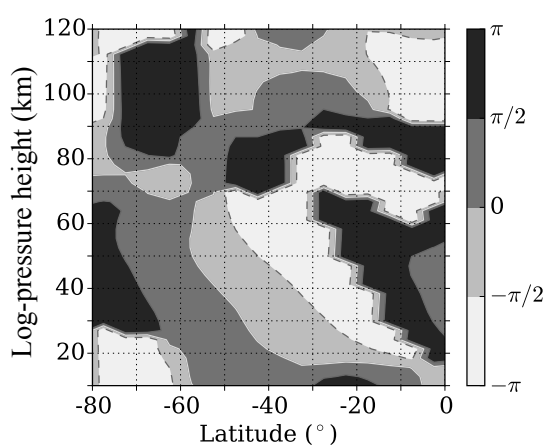

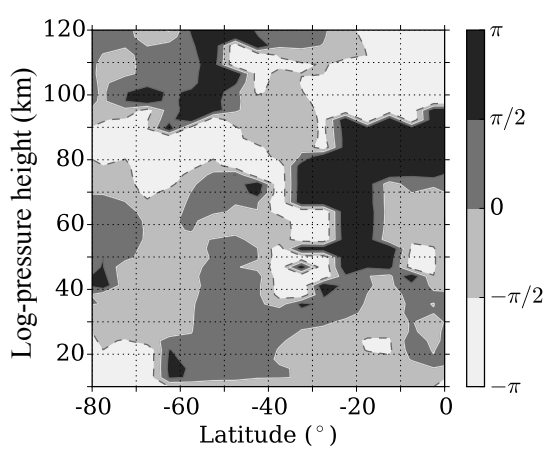

Figure 11. Run1 zonal wind SPW1 phases, SPW forcing only through lower boundary fields (a). Run 3 zonal GW acceleration SPW1 phases, SPW forcing only through non-zonal 2-D GW distribution (b).

GW forcing are equivalent to the SPW results of Run3, and we do not show further plots of Run4.

\section{Discussion and conclusion}

Run1 serves as a reference here because in the GW parameterization of our model this run includes the initialization of zonal mean GW amplitudes as is done in other mechanistic models as well (e.g., Rose, 1983; Jakobs et al., 1986; Fröhlich et al., 2003a). Generally, the background dynamics are reproduced realistically, but compared to winds from empirical climatologies like the Committee on Space Research (COSPAR) International Reference Atmosphere (CIRA86; Fleming et al., 1990), the Upper Atmosphere Research (UARS) Reference Atmosphere Project (URAP; Swinbank and Ortland, 2003), or the radar-based Global Empirical Wind Model (GEWM; Portnyagin et al., 2004), the winter hemisphere mesospheric jet between 50 and $60^{\circ} \mathrm{S}$ (Fig. 2b) appears to be relatively strong with wind speeds up to $110 \mathrm{~m} \mathrm{~s}^{-1}$. Note, however, that the GEWM does not include radar winds between $44^{\circ} \mathrm{S}$ (Christchurch) and $68^{\circ} \mathrm{S}$ (Rothera). Thus, GEWM cannot be used as a validation. The URAP climatology also does not directly use satellite winds around $60^{\circ} \mathrm{S}$ in the MLT. The strong zonal wind jet in the model is mainly a result of the strong polar night jet introduced into the model below $30 \mathrm{~km}$ by the ERA-Interim climatology. The zonal wind at the stratopause reaches more than $80 \mathrm{~m} \mathrm{~s}^{-1}$, which is in agreement with climatologies (Waugh and Polvani, 2010).

Below $60 \mathrm{~km}$, the amplitudes and latitudinal distribution of SPW1 and SPW2 in Run1 broadly correspond to those reported by, for example, Guryanov and Fahrutdinova (2014). The temperature maximum above $70 \mathrm{~km}$ is somewhat larger than the one reported by Mukhtarov et al. (2010) based on SABER satellite analyses up to $50^{\circ} \mathrm{S}$. As observed in our experiments, they also show a secondary maximum of SPW1 in temperature, but the location is slightly below our maximum at about $40 \mathrm{~km}$ altitude and $50^{\circ} \mathrm{S}$. In zonal wind, the double peak structure in SPW1 is well reproduced but
Guryanov and Fahrutdinova (2014) show a similar structure in SPW2, which is not clearly seen in our model. For the meridional wind SPW1 we find a secondary maximum at about $75^{\circ} \mathrm{S} / 35 \mathrm{~km}$ which is also seen in the satellite data, but in our simulations it is slightly more poleward and larger in magnitude.

Taking into account non-zonal structures in GW activity (Run2) leads to a weaker zonal mean winter wind jet in its upper part, and modifications of the meridional/vertical wind structure as well, connected with warming in the midlatitude mesopause region and cooling of the mesosphere. In the $\mathrm{SH}$ winter, GW forces an increase of stratospheric and mesospheric SPW1 amplitudes by approximately $10 \%$, except for the region of the upper part of the zonal wind jet where SPWs are in background flow and SPWs in GW acceleration are out of phase.

The SPW1 in GW flux due to the non-zonal forcing, is in phase with the GW flux due to SPW1 filtering below $70 \mathrm{~km}$. However, above the two GW flux waves are out of phase, as is the case with the GW acceleration and the zonal wind SPW. Therefore in the upper mesosphere we have partly reduced GW SPW1, and finally a smaller SPW1 in mean winds also. For SPW2, this is not the case, but its amplitude is smaller and the SPW1 effect dominates the circulation.

GW momentum fluxes produced by our model generally show well-known behavior above $50 \mathrm{~km}$, being positive in the summer hemisphere and negative in the winter hemisphere. However, below $30 \mathrm{~km}$ there is a region in the winter hemisphere $\left(\approx 50^{\circ} \mathrm{S}\right)$ with positive fluxes. These positive fluxes become smaller with increasing height and turn negative above $40 \mathrm{~km}$. At higher altitudes, GW flux magnitude is slightly decreased around $50^{\circ} \mathrm{S}$. This structure may be surprising but similar behavior has been reported by Wright et al. (2017) using satellite measurements. They observed a small region of positive zonal GW momentum flux at $50^{\circ} \mathrm{S}$, $75^{\circ} \mathrm{W}$ in an altitude of $30 \mathrm{~km}$. A large eastward GW momentum flux during local winter has been observed by de Wit et al. (2017) using SAAMER (Southern Argentina Agile Meteor Radar; $53.7^{\circ} \mathrm{S}, 67.7^{\circ} \mathrm{W}$ ) and they explain this with 
secondary GWs due to stratospheric sources over the Andes mountains in connection with large-amplitude mountain waves breaking in the weak stratospheric winds.

To our knowledge, detailed GW-induced SPW forcing due to non-zonal GW structures has not been reported previously in the literature, and so we are not able to show GW SPW comparisons with measurements here.

It may be concluded that indeed non-zonal structures in GW sources force an additional SPW1. In the stratosphere and lower mesosphere, we consequently have larger SPW amplitudes. The secondary interactions involving GW modulation, however, may be complicated and their effect may be different. This of course depends on the phase of the SPW1 relative to the longitude of the Andes. We have used a longterm mean SPW phases in the model, and individual years may differ.

Code and data availability. The MUAM model code can be obtained from the corresponding author on request. Radio occultation data are freely available from UCAR on http://cdaac-www.cosmic. ucar.edu/cdaac/products.html.

Author contributions. FL designed and performed the MUAM model runs. CJ together with FL drafted the first version of the text. TS provided GPS RO potential energy fields. PA reviewed GW activity as observed by GPS RO. AdlT substantially contributed to the analysis and interpretation of the results.

Competing interests. The authors declare that they have no conflict of interest.

Acknowledgements. We would like to thank the FORMOSAT3/COSMIC teams in Taiwan and the USA for the radio occultation data, and for making them freely available for the scientific user community (http://cdaac-www.cosmic.ucar. edu/cdaac/products.html). This study was supported by BMBF under grant 01DN14001 and by MINCyT under grant BID-PICT 1097. We further acknowledge support from the German Research Foundation (DFG) and Universität Leipzig within the program of Open Access Publishing.

The topical editor, Andrew J. Kavanagh, thanks two anonymous referees for help in evaluating this paper.

\section{References}

Alexander, M. J., Geller, M., McLandress, C., Polavarapu, S., Preusse, P., Sassi, F., Sato, K., Eckermann, S., Ern, M., Hertzog, A., Kawatani, Y., Pulido, M., Shaw, T. A., Sigmond, M., Vincent, R., and Watanabe, S.: Recent developments in gravity-wave effects in climate models and the global distribution of gravitywave momentum flux from observations and models, Q. J. Roy.
Meteor. Soc., 136, 1103-1124, https://doi.org/10.1002/qj.637, 2010.

Alexander, P., Luna, D., Llamedo, P., and de la Torre, A.: A gravity waves study close to the Andes mountains in Patagonia and Antarctica with GPS radio occultation observations, Ann. Geophys., 28, 587-595, https://doi.org/10.5194/angeo-28-587-2010, 2010.

Alexander, P., de la Torre, A., Schmidt, T., Llamedo, P., and Hierro, R.: Limb sounders tracking topographic gravity wave activity from the stratosphere to the ionosphere around midlatitude Andes, J. Geophys. Res.-Space, 120, 9014-9022, https://doi.org/10.1002/2015JA021409, 2015.

Andrews, D. G., Holton, J. R., and Leovy, C. B.: Middle Atmosphere Dynamics, Academic Press Inc. (London) Ltd., 1987.

Baumgaertner, A. J. G. and McDonald, A. J.: A gravity wave climatology for Antarctica compiled from Challenging Minisatellite Payload/Global Positioning System (CHAMP/GPS) radio occultations, J. Geophys. Res.-Atmos., 112, D05103, https://doi.org/10.1029/2006JD007504, 2007.

CDAAC: CDAAC Data Access, available at: http://cdaac-www. cosmic.ucar.edu/cdaac/products.html (last access: July 2017), 2015.

Dee, D. P., Uppala, S. M., Simmons, A. J., Berrisford, P., Poli, P., Kobayashi, S., Andrae, U., Balmaseda, M. A., Balsamo, G., Bauer, P., Bechtold, P., Beljaars, A. C. M., van de Berg, L., Bidlot, J., Bormann, N., Delsol, C., Dragani, R., Fuentes, M., Geer, A. J., Haimberger, L., Healy, S. B., Hersbach, H., Hólm, E. V., Isaksen, L., Kållberg, P., Köhler, M., Matricardi, M., McNally, A. P., Monge-Sanz, B. M., Morcrette, J.-J., Park, B.-K., Peubey, C., de Rosnay, P., Tavolato, C., Thépaut, J.-N., and Vitart, F.: The ERA-Interim reanalysis: configuration and performance of the data assimilation system, Q. J. Roy. Meteor. Soc., 137, 553-597, https://doi.org/10.1002/qj.828, 2011.

de la Torre, A. and Alexander, P.: Gravity waves above Andes detected from GPS radio occultation temperature profiles: Mountain forcing?, Geophys. Res. Lett., 32, L17815, https://doi.org/10.1029/2005GL022959, 2005.

de la Torre, A., Schmidt, T., and Wickert, J.: A global analysis of wave potential energy in the lower stratosphere derived from 5 years of GPS radio occultation data with CHAMP, Geophys. Res. Lett., 33, L24809, https://doi.org/10.1029/2006GL027696, 2006. de la Torre, A., Alexander, P., Hierro, R., Llamedo, P., Rolla, A., Schmidt, T., and Wickert, J.: Large-amplitude gravity waves above the southern Andes, the Drake Passage, and the Antarctic Peninsula, J. Geophys. Res.-Atmos., 117, D02106, https://doi.org/10.1029/2011JD016377, 2012.

de la Torre, A., Alexander, P., Llamedo, P., Hierro, R., Nava, B., Radicella, S., Schmidt, T., and Wickert, J.: Wave activity at ionospheric heights above the Andes Mountains detected from FORMOSAT-3/COSMIC GPS radio occultation data, J. Geophys. Res.-Space, 119, 2046-2051, https://doi.org/10.1002/2013JA018870, 2014.

de Wit, R. J., Janches, D., Fritts, D. C., Stockwell, R. G., and Coy, L.: Unexpected climatological behavior of MLT gravity wave momentum flux in the lee of the Southern Andes hot spot, Geophys. Res. Lett., 44, 1182-1191, https://doi.org/10.1002/2016GL072311, 2017. 
Eckermann, S. D., Preusse, P.: Global Measurements of Stratospheric Mountain Waves from Space, Science, 286, 1534-1537, https://doi.org/10.1126/science.286.5444.1534, 1999.

Ehard, B., Achtert, P., Dörnbrack, A., Gisinger, S., Gumbel, J., Khaplanov, M., Rapp, M., and Wagner, J.: Combination of Lidar and Model Data for Studying Deep Gravity Wave Propagation, Mon. Weather Rev., 144, 77-98, https://doi.org/10.1175/MWR-D-1400405.1, 2016.

Ern, M., Preusse, P., Alexander, M. J., and Warner, C. D.: Absolute values of gravity wave momentum flux derived from satellite data, J. Geophys. Res.-Atmos., 109, D20103, https://doi.org/10.1029/2004JD004752, 2004.

Ern, M., Preusse, P., Gille, J. C., Hepplewhite, C. L., Mlynczak, M. G., Russell, J. M., and Riese, M.: Implications for atmospheric dynamics derived from global observations of gravity wave momentum flux in stratosphere and mesosphere, J. Geophys. Res.-Atmos., 116, D19107, https://doi.org/10.1029/2011JD015821, 2011.

Faber, A., Llamedo, P., Schmidt, T., de la Torre, A., and Wickert, J.: On the determination of gravity wave momentum flux from GPS radio occultation data, Atmos. Meas. Tech., 6, 3169-3180, https://doi.org/10.5194/amt-6-3169-2013, 2013.

Fleming, E. L., Chandra, S., Barnett, J., and Corney, M.: Zonal mean temperature, pressure, zonal wind and geopotential height as functions of latitude, Adv. Space Res., 10, 11-59, https://doi.org/10.1016/0273-1177(90)90386-E, 1990.

Fröhlich, K., Pogoreltsev, A., and Jacobi, C.: The 48 Layer COMMA-LIM Model: Model description, new Aspects, and Climatology, Rep. Inst. Meteorol. Univ. Leipzig, 161189, available at: http://home.uni-leipzig.de/jacobi/medec/2003_ COMMA_LIM.pdf (last access: July 2017), 2003a.

Fröhlich, K., Pogoreltsev, A., and Jacobi, C.: Middle Atmosphere Structure and Dynamics Numerical simulation of tides, Rossby and Kelvin waves with the COMMA-LIM model, Adv. Space Res., 32, 863-868, https://doi.org/10.1016/S02731177(03)00416-2, 2003 b.

Gavrilov, N., Karpova, N., Jacobi, C., and Gavrilov, A.: Morphology of atmospheric refraction index variations at different altitudes from GPS/MET satellite observations, J. Atmos. Sol.-Terr. Phy., 66, 427-435, https://doi.org/10.1016/j.jastp.2004.01.031, 2004.

Geller, M. A., Alexander, M. J., Love, P. T., Bacmeister, J., Ern, M., Hertzog, A., Manzini, E., Preusse, P., Sato, K., Scaife, A. A., and Zhou. T.: A comparison between gravity wave momentum fluxes in observations and climate models, J. Climate, 26, 6383-6405, https://doi.org/10.1175/JCLI-D-12-00545.1, 2013.

Guryanov, V. and Fahrutdinova, A.: Height-latitude structure of stationary planetary waves in the stratosphere and lower mesosphere, Adv. Space Res., 53, 674-688, https://doi.org/10.1016/j.asr.2013.12.010, 2014.

Hindley, N. P., Wright, C. J., Smith, N. D., and Mitchell, N. J.: The southern stratospheric gravity wave hot spot: individual waves and their momentum fluxes measured by COSMIC GPS-RO, Atmos. Chem. Phys., 15, 7797-7818, https://doi.org/10.5194/acp15-7797-2015, 2015.

Jacobi, C., Fröhlich, K., and Pogoreltsev, A.: Quasi twoday-wave modulation of gravity wave flux and consequences for the planetary wave propagation in a simple circulation model, J. Atmos. Sol.-Terr. Phy., 68, 283-292, https://doi.org/10.1016/j.jastp.2005.01.017, 2006.

Jakobs, H. J., Bischof, M., Ebel, A., and Speth, P.: Simulation of gravity wave effects under solstice conditions using a 3-D circulation model of the middle atmosphere, J. Atmos. Terr. Phys., 48, 1203-1223, https://doi.org/10.1016/0021-9169(86)90040-1, 1986.

Kursinski, E. R., Hajj, G. A., Schofield, J. T., Linfield, R. P., and Hardy, K. R.: Observing Earth's atmosphere with radio occultation measurements using the Global Positioning System, J. Geophys. Res.-Atmos., 102, 23429-23465, https://doi.org/10.1029/97JD01569, 1997.

Matsuno, T.: Numerical integration of the primitive equations by a simulated backward difference method, J. Meteorol. Soc. Jpn Ser. II, 44, 76-84, 1966.

Mukhtarov, P., Pancheva, D., and Andonov, B.: Climatology of the stationary planetary waves seen in the SABER/TIMED temperatures (2002-2007), J. Geophys. Res.-Space, 115, A06315, https://doi.org/10.1029/2009JA015156, 2010.

Pogoreltsev, A. I., Vlasov, A. A., Fröhlich, K., and Jacobi, C.: Planetary waves in coupling the lower and upper atmosphere, J. Atmos. Sol.-Terr. Phy., 69, 2083-2101, https://doi.org/10.1016/j.jastp.2007.05.014, 2007.

Portnyagin, Y., Solovjova, T., Merzlyakov, E., Forbes, J., Palo, S., Ortland, D., Hocking, W., MacDougall, J., Thayaparan, T., Manson, A., Meek, C., Hoffmann, P., Singer, W., Mitchell, N., Pancheva, D., Igarashi, K., Murayama, Y., Jacobi, C., Kuerschner, D., Fahrutdinova, A., Korotyshkin, D., Clark, R., Taylor, M., Franke, S., Fritts, D., Tsuda, T., Nakamura, T., Gurubaran, S., Rajaram, R., Vincent, R., Kovalam, S., Batista, P., Poole, G., Malinga, S., Fraser, G., Murphy, D., Riggin, D., Aso, T., and Tsutsumi, M.: Mesosphere/lower thermosphere prevailing wind model, Adv. Space Res., 34, 1755-1762, https://doi.org/10.1016/j.asr.2003.04.058, 2004.

Ratnam, M. V., Tetzlaff, G., and Jacobi, C.: Global and Seasonal Variations of Stratospheric Gravity Wave Activity Deduced from the CHAMP/GPS Satellite, J. Atmos. Sci., 61, 1610-1620, https://doi.org/10.1175/15200469(2004)061<1610:GASVOS>2.0.CO;2, 2004.

Reigber, C., Lühr, H., and Schwintzer, P.: CHAMP mission status, Adv. Space Res., 30, 129-134, https://doi.org/10.1016/S02731177(02)00276-4, 2002.

Rose, K.: On the influence of nonlinear wave-wave interactions in a 3-D primitive equation model for Sudden stratospheric warmings, Beiträge zur Physik der Atmosphäre, 56, 14-41, 1983.

Schmidt, T., Alexander, P., and de la Torre, A.: Stratospheric gravity wave momentum flux from radio occultations, J. Geophys. Res.-Atmos., 121, 4443-4467, https://doi.org/10.1002/2015JD024135, 2016.

Swinbank, R. and Ortland, D. A.: Compilation of wind data for the Upper Atmosphere Research Satellite (UARS) Reference Atmosphere Project, J. Geophys. Res., 108, 4615, https://doi.org/10.1029/2002JD003135, 2003.

Šácha, P., Kuchar, A., Jacobi, C., and Pišoft, P.: Enhanced internal gravity wave activity and breaking over the northeastern Pacificeastern Asian region, Atmos. Chem. Phys., 15, 13097-13112, https://doi.org/10.5194/acp-15-13097-2015, 2015.

Šácha, P., Lilienthal, F., Jacobi, C., and Pišoft, P.: Influence of the spatial distribution of gravity wave activity on the middle at- 
mospheric dynamics, Atmos. Chem. Phys., 16, 15755-15775, https://doi.org/10.5194/acp-16-15755-2016, 2016.

Tsuda, T., Nishida, M., Rocken, C., and Ware, R. H.: A Global Morphology of Gravity Wave Activity in the Stratosphere Revealed by the GPS Occultation Data (GPS/MET), J. Geophys. Res.-Atmos., 105, 7257-7273, https://doi.org/10.1029/1999JD901005, 2000.

Waugh, D. W. and Polvani, L. M.: Stratospheric Polar Vortices, American Geophysical Union, 190, 43-57, https://doi.org/10.1029/2009GM000887, http://pages.jh.edu/ $\sim$ dwaugh1/papers/Waugh_Polvani_2010.pdf, 2010.
Wickert, J., Reigber, C., Beyerle, G., König, R., Marquardt, C., Schmidt, T., Grunwaldt, L., Galas, R., Meehan, T. K., Melbourne, W. G., and Hocke, K.: Atmosphere sounding by GPS radio occultation: First results from CHAMP, Geophys. Res. Lett., 28, 3263-3266, https://doi.org/10.1029/2001GL013117, 2001.

Wright, C. J., Hindley, N. P., Hoffmann, L., Alexander, M. J., and Mitchell, N. J.: Satellite Measurements of Stratospheric GravityWaves over the Andes/Drake Passage Region Using a 3D S-Transform Technique, Atmos. Chem. Phys. Discuss., https://doi.org/10.5194/acp-2017-128, in review, 2017. 